\begin{tabular}{|l|l|l|}
\hline \multicolumn{2}{|c|}{ PublisherInfo } \\
\hline \hline PublisherName & $:$ & BioMed Central \\
\hline \hline PublisherLocation & $:$ & London \\
\hline \hline PublisherImprintName & $:$ & BioMed Central \\
\hline \hline
\end{tabular}

\title{
Thalidomide in patients with metastatic breast cancer
}

\begin{tabular}{|l|l|l||}
\hline \multicolumn{2}{|c|}{ ArticleInfo } \\
\hline \hline ArticleID & $:$ & 3729 \\
\hline \hline ArticleDOI & $:$ & $10.1186 /$ bcr-2000-66692 \\
\hline \hline ArticleCitationID & $:$ & 66692 \\
\hline \hline ArticleSequenceNumber & $:$ & 95 \\
\hline \hline ArticleCategory & $:$ & Paper Report \\
\hline \hline ArticleFirstPage & $:$ & 1 \\
\hline \hline ArticleLastPage & $:$ & 4 \\
\hline \hline & & RegistrationDate : 2000-8-21 \\
\hline ArticleHistory & $:$ & OnlineDate \\
\hline \hline ArticleCopyright & $:$ & Current Science Ltd2000-8-21 \\
\hline \hline ArticleGrants & $:$ & \\
\hline \hline ArticleContext & $:$ & 1305822 \\
\hline \hline
\end{tabular}


Richard de Boer, ${ }^{\text {Aff1 }}$

Aff1 Austin and Repatriation Medical Centre, Victoria, Australia

\section{Keywords}

Angiogenesis, breast cancer, thalidomide

\section{Introduction}

Thalidomide, a derivative of glutamic acid, was first used as an antinausea agent for pregnant women in the 1950s. It was removed from the market after it was found to cause limb malformations in the developing foetus. Thalidomide has a number of interesting properties, including an immunitymodulating effect that might result from inhibition of lymphocyte proliferation. This property has been used in the treatment of leprosy, cutaneous lupus, recurrent erythema multiforme and transplantationassociated graft-versus-host disease. Thalidomide has also been tested in cancer patients with some responses seen in patients with multiple myeloma and recurrent gliomas. The antitumour effect of thalidomide is thought to be due to its direct antiangiogenic effects. It has been experimentally shown to inhibit angiogenesis, in particular angiogenesis induced by vascular endothelial growth factor (VEGF) and basic fibroblastic growth factor (bFGF).

\section{Aims}

To determine the efficacy, safety, pharmacokinetics, and effect on serum angiogenic growth factors of thalidomide in patients with metastatic breast cancer (MBC).

\section{Comments}

This was a very well performed and reported study. Whilst this type of patient is always difficult to treat, the lack of any defined responses was disappointing. Thalidomide was certainly absorbed as most patients had detectable plasma levels; however, there appeared to be little consistent effect upon circulating markers of angiogenic activity and certainly little clinical antitumour effect. The use of biological agents such as the angiogenesis inhibitors has raised a number of difficult issues in terms of trial design and measurement of biological activity. Unlike the classical chemotherapy agents, these 
biological agents may be tumorostatic rather than tumorocidal, thus making assessment of activity much more difficult. This study attempted to overcome this with careful analysis of plasma markers. Another method could be serial biopsies of tumour with measurement of tumour vessel density etc. Obviously, thalidomide does not appear to be useful in this setting and further studies that include different patient populations and/or combinations with other agents will need to be performed.

\section{Methods}

Eligible patients had progressive $\mathrm{MBC}$ and had undergone no more than three prior chemotherapy regimens, but unlimited previous hormonal or biologic therapy. Cerebral metastases or recent major surgery were exclusion criteria. Patients were randomised to receive either $200 \mathrm{mg}$ or $800 \mathrm{mg}$ (to be escalated to $1200 \mathrm{mg}$ over 4 weeks if there was no toxicity) of thalidomide daily. Tumour assessment was performed every 8 weeks. Pharmacokinetics and growth factor serum levels (bFGF, VEGF, and tumour necrosis factor [TNF]- $\alpha$ ) were evaluated. Plasma levels of the matrix metalloproteinases MMP-2 and MMP-9 were also measured. Treatment continued until disease progressed or unacceptable toxicity developed.

\section{Results}

Patients $(n=28)$ were recruited with 14 at each dose level. The two groups were comparable in terms of age and prior chemotherapy. No patient had a true partial or complete response. At the $200 \mathrm{mg}$ dose level, two patients had stable disease at 8 weeks, one of whom was removed from study at week 11 due to grade 3 neuropathy and the other had progressive disease at week 16 . The other 12 patients had progressive disease at or before 8 weeks. In the $800 \mathrm{mg}$ arm, 13 patients had progressive disease at or before 8 weeks and one refused to continue treatment. Seven patients required a dose reduction due to somnolence. One patient had a dose increase to $1000 \mathrm{mg}$ and four patients' dose increased to $1200 \mathrm{mg}$. Adverse events that did not require dose modifications included constipation, skin rash, fatigue, nausea, arrhythmia, and hypotension. Thalidomide levels were measurable in most patients and oral clearance was the same for the two initial dose levels. There was a mean percentage decrease in bFGF levels, and mean percentage increases in VEGF and TNF- $\alpha$ levels. Only the change in the TNF- $\alpha$ levels was significant. Plasma levels of MMP-2 remained largely unchanged, and levels of MMP-9 varied with no obvious pattern.

\section{Discussion}

In this group of patients, thalidomide, at either low or high dose, had little anticancer effect. The low dose was well tolerated, but there was significant toxicity, in particular somnolence, in the high-dose 
arm. Studies of markers of angiogenesis provided little information on possible mechanisms of action. Interestingly the one patient who almost achieved a partial response had a decrease in circulating levels of TNF- $\alpha$. This ability of thalidomide to decrease TNF- $\alpha$ levels has been noted in a number of disease types, and it may be one mechanism by which thalidomide acts.

\section{References}

1. Baidas SM, Winer EP, Fleming GF, Harris L, Pluda JM, Crawford JG, Yamauchi H, Isaacs C, Hanfelt J, Tefft M, Flockhart D, Johnson MD, Hawkins MJ, Lippman ME, Hayes DF: Phase II evaluation of thalidomide in patients with metastatic breast cancer. J Clin Oncol . 2000, 18: 2710-2717. 